\title{
The Role of Family and Friends in Return Migration and Its Labor Market Outcomes
}

\author{
Brian Joseph Gillespie ${ }^{1}$ (D) Clara H. Mulder $^{1} \cdot$ Christiane von Reichert $^{2}$
}

Received: 21 July 2020 / Accepted: 20 March 2021 / Published online: 1 April 2021

(c) The Author(s) 2021

\begin{abstract}
Drawing on survey data on individuals' motives for migration in Sweden $(N=2172)$, we examine the importance of family and friends for return versus onward migration, including their importance for different age groups and in different communities on the rural-urban spectrum. The results point to a significant relationship between the importance of family and return versus onward migration, with family importance decreasing with age among returning migrants. At the same time, the importance of friends for returning increases with age. The findings did not suggest a significant relationship between urbanicity and returning versus migration elsewhere. Based on a subset of respondents who were employed prior to migrating $(n=1056)$, we further examined labor market outcomes for onward versus returning migrants. The results broadly indicate that return migrations are linked to lower likelihoods of labor market deterioration and improvement, suggesting greater labor market stability for return vis-à-vis onward migrations. However, the importance of family for returning (versus moving elsewhere) is associated with higher likelihoods of labor market deterioration and improvement compared with staying the same, indicating greater volatility in labor market outcomes when the importance of family is considered.
\end{abstract}

Keywords Family $\cdot$ Friends $\cdot$ Labor market outcomes $\cdot$ Life course $\cdot$ Return migration · Urbanicity

Brian Joseph Gillespie

b.j.gillespie@rug.nl

1 Population Research Centre, Faculty of Spatial Sciences, University of Groningen, Groningen, The Netherlands

2 Department of Geography, University of Montana, Missoula, USA 


\section{Introduction}

For quite some time, return migration has received scholarly attention as a unique type of migration, with different characteristics and causes than other types (e.g., DaVanzo \& Morrison, 1981; Newbold \& Liaw, 1990). For example, return migration is frequently related to adverse life events, such as dropping out of college or university (Mulder et al., 2020) and separation (Spring et al., 2021). Return migration makes up a substantial share of internal migration in general, and an even greater share of migration among those who migrated previously ("repeat" migrants). Based on a broad variety of definitions, often determined by available data, return migrations ranged from under $20 \%$ to over $30 \%$ of all internal migrations across a host of countries: Australia, Canada, Finland, Germany, Spain, and the US (Niedomysl \& Amcoff, 2011, based on a review of the return migration literature), and comprised more than half of the migrations from large Swedish cities among a specific population of young repeat migrants (Mulder et al., 2020).

Studies indicate that an important draw to return migrate is having kin at one's region of origin - this includes family in general (von Reichert et al., 2014a, b), parents (Zorlu \& Kooiman, 2019), and siblings (Mulder et al., 2020). The role of nonresident family in migration has also become clear from studies that do not specifically focus on return migration but on moving in the direction of parents and adult children (e.g., Michielin et al., 2008; Pettersson \& Malmberg, 2009; Thomas \& Dommermuth, 2020) or siblings (Mulder et al., 2020) and from analyses of motivations for migration (Thomas, 2019; Thomas et al., 2019).

While family is at the core of social networks, close friends are also importantand the importance of each might be conflated since both are usually present in individuals' origin regions (Gillespie \& Mulder, 2020). Remarkably, the role of friends in migration is rarely considered (for a notable exception, see Belot \& Ermisch, 2009); although Niedomysl and Amcoff (2011) did show that "social motives," based on an open-ended measure of individuals' primary reason for moving, matter for return migration. Thus, our first main objective is to examine the importance not only of family but also friends for return-versus onward-migration.

The roles that different types of social relationships play are known to change over the life course (Gillespie et al., 2015a). In accordance with these changing roles, the importance of family and friends for migration might also change with age. Given that previous research on the importance of family for return migration has been based on a small sample or specific age range (e.g., Mulder et al., 2020; von Reichert et al., 2014a; Zorlu \& Kooiman, 2019), there has been no systematic exploration of potential differences across age groups. As such, an additional objective of our study is to examine how the importance of family and friends for return migration varies based on individuals' age group. There is also evidence of a difference in the role of social ties between urban and rural areas (Hofferth \& Iceland, 1998). Therefore, we also examine whether and how the importance of family and friends for return migration differs by urbanicity.

Research on the precursors of return migration has often been cast in dichotomous-typically economic-terms, with labor market success versus failure as 
the impetus for moving back versus moving onward (e.g., DaVanzo \& Morrison, 1981). Another important issue to explore is labor market consequences after return migration. As DaVanzo (1981) argued, location-specific capital (e.g., by way of family and friends) might facilitate successful re-integration into labor markets after returning. In the empirical literature on the labor market outcomes of migration, however (e.g., Gillespie et al., 2020; Korpi \& Clark, 2017), the specific outcomes of return migration within a country have rarely been examined. A noteworthy exception is a study by von Reichert et al. (2011), who found detrimental labor market outcomes to be common among migrants returning to rural areas of the United States. Another study on return migrants in China demonstrated a high likelihood of self-employment among return migrants when compared to nonmigrants ( $\mathrm{Wu}$ et al., 2018). Given the limited work with this focus, the second main objective of our study is to examine labor market outcomes associated with Swedish return migration, especially in light of return migration for family and friends.

We draw on a sample of repeat migrants in Sweden, which is unique in the sense that register data on migration behavior were matched to a survey that included detailed measurements of migration motives. We use logistic regression to explore return versus onward migration, and multinomial logistic regression of deterioration or improvement in labor market outcomes (versus staying the same) following migration.

\section{Literature Review}

\section{Return Versus Onward Migration: The Importance of Nonresident Family and Friends}

Nonresident family forms an important source of both support and social capital. For example, grandparents are important providers of childcare (Hank \& Buber, 2009), and siblings and friends also provide support to each other (Voorpostel \& van der Lippe, 2007). Next to education, jobs, and amenities, nonresident family could therefore form an important attraction factor for migration (Mulder, 2018), and this could also hold for friends.

The issue here is how, among repeat movers, the importance of family and friends differs between return and onward migration. An obvious difference between return and onward migrants is that onward migrants move to a place they might know from visits but where they have never lived before, whereas return migrants move to a familiar environment. Although the reasons for returning likely vary widely, we assume that return migration is always motivated by some form of location-specific capital at the origin. Next to other types of capital, such as a home or land owned by the family or human capital (e.g., in the form of knowledge of the local labor market), social capital - a local social network - is a prime example of this location-specific capital. Given that distances between family members' places of residence tend to be short (Kolk, 2017; Mulder \& Kalmijn, 2006), it is likely that those who have migrated (comprising our study population) are likely to have family "left behind" in 
their region of origin. We therefore might expect return migrants to be particularly likely to be motivated by family-more so than onward migrants. The same reasoning could also be applied to friends.

From recent studies using register data for entire populations, we indeed have strong indications that having family living in the home region plays an important role in young adult return migration. As Zorlu and Kooiman (2019) found for the Netherlands, young adults are much more likely to return to the home region (rather than not move) if a parent lives there. Mulder et al. (2020) show the same for Sweden, and also show that the likelihood of return migration is greater if a sibling lives in the home region. Many of these young adult moves — but certainly not all—are directed toward the parental home (see also Olofsson et al., 2020). ${ }^{1}$ For the United States, a recent study by Spring et al. (2021) based on the Panel Study of Income Dynamics showed that return migration to the county where someone grew up was more likely if a parent, sibling, or child lived in that county.

Based on these previous studies, it cannot be ruled out that moves toward family are a by-product of moves unrelated to family considerations. Evidence that nonresident family is indeed what return migrants consider in their migration decisions is scarce, and evidence that friends are important is even scarcer. As an exception, findings from a small-scale survey among youth returning to a rural area in the Netherlands demonstrated that parents were mentioned most frequently as important to return moves, with friends second and other family third (the rural environment was fourth and a partner fifth; Haartsen \& Thissen, 2013). Qualitative work in the United States also showed that parents were of prime importance for return migrants to rural areas (von Reichert et al., 2013). Using the same data as this study, Niedomysl and Amcoff (2011) demonstrated that social reasons were among the most frequently mentioned motivations for migration, and even more so for return migrants than for nonreturn migrants. However, they did not distinguish motives related to nonresident family and motives related to friends from other social motives, such as those related to resident family or partners.

Given these considerations, our first two general hypotheses are:

H1a The importance of being close to nonresident family is positively associated with return migration compared with onward migration.

H1b The importance of being close to friends is positively associated with return migration compared with onward migration.

\section{The Importance of Family and Friends Over the Life Course}

To derive hypotheses on how the importance of family and friends for return migration would change over the life course, we rely on two different arguments, leading

\footnotetext{
${ }^{1}$ For recent work on returning to the parental home, see Sironi and Billari (2019) for the USA; Stone, Berrington and Falkingham (2014) for the UK.
} 
to competing hypotheses. The first is related to the composition of close social relationships in terms of family versus friends. The young adult years are typically a time when friendships feature prominently in close networks. For example, in the U.S., young adults reported the greatest number of close friends they could confide in, with numbers consistently decreasing over age (Gillespie et al., 2015a).

With age, family relations tend to gain in importance, as when midlife individuals and/or their aging parents relocate for the provision of the parents' later life care (Artamonova et al., 2020). In a U.S. longitudinal study, social support from adult children increased substantially between parents aged 57-60 and 69-72 (Silverstein et al., 2002). According to Rossi and Rossi (1990), "kin embeddedness," a scale measuring the relative importance of family versus friends in social networks, increases from the 30s until old age. Given these changes in the differential significance of social relationships by age, we hypothesize:

$\mathrm{H} 2 \mathrm{a}$ The importance of family for return migration, compared with onward migration, increases with age.

H2b The importance of friends for return migration, compared with onward migration, decreases with age.

The second argument is related to the likelihood of having family and friends in the home region. The very strong age specificity of migration (Bernard et al., 2016) has several consequences for the likelihood of having family living in the home region. Young adults are much more likely to migrate than their parents. After young adults migrate from the region where they grew up, it is therefore likely that their parents still live in the home region, and thus, they can return to them. Young adults are also in the life course phase of transitioning to independence, which comes with entering and finishing tertiary education and entering the labor market. In this phase, returns to the parental home (Gillespie, 2020; Gillespie \& Lei, 2020) and region (Mulder et al., 2020; Zorlu \& Kooiman, 2019) occur frequently, possibly for support from parents. Those who recently had a child are also more likely to move toward their parents than those without children, likely for childcare assistance (Michielin et al., 2008).

For older adults who moved away from the home region in young adulthood, there is a lower likelihood that the parents are still alive (and available to return to). Given the same age specificity, it is more likely that anyone who lives away from home left that region before having children (or when the children were young), rather than moving away from adult children in the home region. It is therefore not very likely that older migrants have adult children in the home region that they can return to. Those who do move toward adult children [for example to move close to grandchildren (van Diepen \& Mulder, 2009)] would then be more likely to move onward. These considerations lead to a competing hypothesis compared with H2a:

H3a The importance of family for return migration, compared with onward migration, decreases with age. 
For friends, the situation is different. Childhood and young adolescent friendships tend to be characterized by low stability (Poulin \& Chan, 2010). Therefore, although some young adults who migrated may want to return to high school friends, many will have their most important friends at the location where they moved. Among older adults, the chances are greater that someone moved away after young adulthood, and thus, after developing more important friendships in the home region. Bonds of friendship, typically with same age peers, might be a draw for return migration in late adulthood. Even though the number of close friends tends to decrease over the life course, satisfaction with friends tends to increase with age (Gillespie et al., 2015a, b), possibly adding to the importance of friends in the life of older adults. We therefore hypothesize, in contrast with $\mathrm{H} 2 \mathrm{~b}$ :

H3b The importance of friends for return migration, compared with onward migration, increases with age.

\section{Urban Versus Rural Areas}

Urban areas are the main centers of employment and tertiary education, and form an attraction factor for the migration of young adults from less urban areas [e.g., Lundholm (2012) for Sweden]. Conversely, young adults who live with their parents in urban areas have less incentive to move a long distance when they leave home (Mulder \& Clark, 2000). As a consequence, those living in urban areas tend to live farther from their parents (but closer to their adult children) than those living in rural areas (Mulder \& Kalmijn, 2006; Van der Pers \& Mulder, 2013). Thus, those in urban areas are more likely to have parents in rural areas to whom they can return. These patterns of migration and proximity likely lead to a difference between return and onward migration, such that return moves are more frequently directed to rural areas than onward moves. For older adults (55+), Lundholm (2012) indeed detected higher propensities to return to rural than to urban areas of Sweden. ${ }^{2}$

The "escalator-region" literature (Champion, 2012; Fielding, 1992) also suggests that moves off the escalator (that is, from large metropolitan areas to less urban areas) tend to occur for reasons other than employment. Although this literature does not explicitly mention family, part of these moves could be family-related returns to rural areas. Further, as Hofferth and Iceland (1998) have shown, exclusive social exchange with kin occurs more frequently in rural than in urban areas. Thus, people growing up in rural communities perhaps develop stronger family ties, showing up as a rural effect when the underlying draw is family. We therefore hypothesize:

H4 Among migrants, being close to family and friends will be more important for returns to rural, as opposed to urban, municipalities.

\footnotetext{
${ }^{2}$ It should be noted, however, that for young adults in the Netherlands, Zorlu and Kooiman (2020) found a higher propensity to return to more urbanized than rural home regions.
} 


\section{The Labor Market Outcomes of Return Migration}

According to Sjaastad's (1962) classical work on how migration can be viewed as an investment increasing the productivity of human capital, one should expect income gains after migration. However, as Korpi and Clark (2017) have argued, not all migrants experience these income gains. Migrants might accept low labor market returns when compensated with noneconomic benefits, such as higher quality of life and/or amenities (e.g., von Reichert \& Rudzitis, 1992). Return migration, compared with onward migration, will be more frequently related to noneconomic considerations. In the 2011 Swedish study by Niedomysl and Amcoff (using the same data we use for this paper), common reasons for return migration were not only "social" but also "other" reasons, which included all other reasons except employment, education, housing, environment, and social reasons. In von Reichert et al.'s (2014a) study of return migration to rural areas in the United States, respondents frequently spoke of family in the origin region as a motive for returning, while also community context, the environment, and familiarity with the area. Because of the prevalence of noneconomic reasons for returning, it is likely that return migrants sacrifice economic outcomes for other benefits.

Indeed, as von Reichert et al. (2011) demonstrated, return migrants frequently brought up career sacrifices they had made in order to return home (e.g., to raise their children in a familiar environment). At the same time, we recognize that there might be a share of return migrants who use the location-specific capital they left behind in their home region to advance their careers (DaVanzo, 1981) or return to take over a family business (von Reichert et al., 2011). Our hypothesis reads:

H5 Among employed migrants, return migration will be associated with worse labor market outcomes than onward migration.

Likewise, while those moving for work are likely to achieve economic benefits from migration, those who move for other reasons might sacrifice economically. Among these other reasons, "migration for family might be thought especially detrimental to labor market outcomes, with social and familial roles and responsibilities working to constrain individual choices and potentially restrict opportunities for migrations that could otherwise prove beneficial from an employment or occupational perspective" (Gillespie et al., 2020). Migration for family reasons may also be associated with adverse circumstances, such as divorce (Wall \& von Reichert, 2013). In these cases, finding refuge with family might be perceived as more important than economic outcomes. Hypothesis 6 therefore reads:

H6 Among employed migrants, a higher importance placed on being close to family will be associated with worse labor market outcomes.

The combination of return migration and a great importance of family considerations in the migration decision could lead to different labor market outcomes from those of return migration or migration for family alone. For example, among 
migrants returning for family, those who are in adverse circumstances and need help may be overrepresented. Conversely, for some of those returning to family, the labor market disadvantages associated with return migration might be offset because family members can form an important source of capital. For instance, family may provide assistance with finding a job or the migrant might take over the family business. We therefore explore whether the importance of family for migration moderates the relationship between return migration and labor market outcomes-but we do not formulate a hypothesis on the direction of this moderation.

\section{The Swedish Context}

Sweden is known, especially when compared to the U.S. or the UK, for policies promoting egalitarianism, offering social support systems, and mitigating adverse market outcomes. These policies might buffer migration risks. Sweden's relative lack of family orientation (Reher, 1998) is also noteworthy, making it an interesting case for the study of return migration, namely because individuals are likely to be less dependent on their family for support than in other countries. In their study of return migration in Sweden, Niedomysl and Amcoff (2011) do, however, find that social motives matter much to Swedish migrants. It is also a fairly large country with high rates of mobility (Bell et al., 2018) - and internal migration is a main force in redistributing populations toward larger urban centers and away from the rural interior of Northern Sweden (Shuttleworth et al., 2017; Grunfelder et al., 2020).

\section{Data/Methods}

\section{Data}

The data were derived from the postal survey Swedish Motives for Moving (see Niedomysl \& Malmberg, 2009; Niedomysl, 2011). They are based on a sample of 10,000 migrants in 2007 from the population of 244,704 migrants who had moved at least $20 \mathrm{~km}$ in the prior year, derived from the Swedish population register. The survey, which was implemented in collaboration with Statistics Sweden, was designed to tap into household-level migration experiences in Sweden, including migration motivations, the importance of several factors for moving (e.g., family and friends), employment status, and demographic characteristics. The sample was stratified by gender, age (four groups between 18 and 74 years old), and migration distance (20-35 km, 36-50 km, 51-100 km, and $101+\mathrm{km}$ ). After two reminders, 4909 migrants returned completed questionnaires.

Certain groups were unequally represented in the completed surveys. Women were more likely than men to complete the survey, older persons more likely than younger, native-born individuals were more likely than foreign-born, higher income respondents were more likely than lower income, and married individuals were more likely than the unmarried. Sampling weights, designed by Statistics Sweden, helped to correct for these disproportionate representations. 


\section{Sample Construction}

To examine return migration versus onward migration, we only considered migrants who lived outside their county of birth prior to the move. From that subset, we identified returning migrants as those who moved from outside their county of birth back to their origin municipality. People moving from outside their county of birth to another municipality were identified as onward migrants. ${ }^{3}$ That is, if the pre-move municipality was not located in the respondent's county of birth and they did not self-report a return to their origin municipality, they were classified as having moved onward. However, since individuals might be able to move $20 \mathrm{~km}$ and still remain within their municipality, an additional restriction was that the pre-move municipality was not the same as the post-move municipality. Owing to these restrictions, this yielded an analytic sample of 2172 for the first set of analyses exploring individuals' likelihood of return migration.

For the second set of analyses of labor market outcomes following return or onward moves, only those who were employed prior to moving were considered. This led to an analytic sample of 1056.

\section{Measures}

\section{Dependent Variables}

To analyze the role of family and friends for return versus onward migration (Hypotheses 1-4), the dependent variable was returning to the origin municipality versus migration elsewhere. The survey asked whether or not the respondent grew up in the municipality that they moved to. There was also a qualifier: "What is meant by "grew up" is where you mainly lived until your 16th birthday." The codes for the migration measure were (0) for respondents who moved onward-that is, moved but did not return - and (1) for respondents who returned to their origin municipality.

For the analyses of the role of onward and return migration in labor market outcomes (Hypotheses 5 and 6), the dependent variable was a self-reported change in labor market outcomes associated with the move. A survey item asked, "How has the move affected your work conditions regarding...?" Recognizing that work conditions encompass more than salaries, we included three items: (1) Salary (2) Work Opportunities, and (3) Interesting Work Tasks, with the following Likert-type response options: (1) Much better, (2) Somewhat better, (3) Unchanged, (4) Somewhat worse, and (5) Much worse. The responses were reverse-coded so that higher scores indicated improvements in labor market outcomes. Responses were then collapsed into three categories, representing deteriorations (1), no change (2-the reference category), or improvements (3). They were then summed to create a scale, ranging from 3 to 9 , with higher scores indicating better labor market outcomes.

\footnotetext{
${ }^{3}$ Migrants who lived in their county of birth prior to the move could be first-time migrants or repeat migrants. There was no way of separately identifying these groups and so we did not include them in the sample.
} 
Confirmatory factor analysis validated the use of the composite measure $(\alpha=0.78)$. We also classified individuals who were employed prior to moving and unemployed after the move $(n=54)$ as having experienced a labor market deterioration.

\section{Primary Variables}

A closed-ended survey item asked, "How important were the following factors for your decision to move...?" "Being close to relatives" and "Being close to friends" were among the 12 items listed, with response options ranging from (0) "Not important" to (4) Extremely important." The survey also collected information about individuals' open-ended motives for moving, which was used in the previous work based on these data (Gillespie et al., 2021; Niedomysl \& Amcoff, 2011). We preferred the "importance" measures because they allow for assessment of the degree of importance (beyond simply mentioning friends/family as a motive). For instance, individuals who mentioned other reasons, such as housing, as their motive for migration still reported on the ordered level of importance of being close to relatives and friends for their move. However, we conducted sensitivity analyses using individuals' migration motives, which we discuss at the end of "Results" section.

We used a categorical measure for age based on the stratification categories of the sampling design (18-25, 26-37, 38-59, and 60-74). Additionally, rural-urban classifications of the municipality of destination (i.e., urbanicity) are based on Statistics Sweden's classifications of population size and commuting patterns-the categories are: large city, suburban municipality, medium-sized town, medium-sized commuter municipality, medium-sized commuter town with low commuter population, small town, commuting municipality near a small town, rural municipality, and rural municipality with visitor industry. These items were reverse-coded and collapsed into three categories: (1) small town or rural, (2) medium town, and (3) suburb or large city.

In the analyses of labor market outcomes, where return migration versus onward migration is an independent variable, we again used respondents' self-report of return migration. The codes for the return migration measure were $(0)$ the respondent moved elsewhere and (1) the respondent returned to their origin municipality.

\section{Control Variables}

Several sociodemographic variables are measures at the individual-and householdlevels. First, we included gender (female $=1$, male $=0$ ). Education is an ordered variable classifying individuals as having an elementary school education, high school, some college, or a college degree. A measure for marital/partner status indicated whether the respondent was unpartnered, partnered/cohabiting, or married after the migration took place. A dichotomous measure indicated whether or not the respondent had any coresidential children (1), else (0). Housing tenure marked individuals' post-migration housing situation as owning, renting, or some other type of housing

\footnotetext{
${ }^{4}$ In the remainder of the paper, we use "relatives" and "family" interchangeably.
} 
situation. Income is based on information on respondents' log-transformed household income in 2005 prior to moving. A measure for employment indicates whether the respondent was employed, unemployed, enrolled in school, retired, or some other labor force status before moving.

Based on aggregate data from Statistics Sweden, regional variables identify post-migration attractions at the municipal level in 2007. The continuous variables include the unemployment rate and also the logged average municipal housing cost. A dichotomous measure indicated whether or not there was a higher education institution in the post-migration municipality.

For the analyses of labor market outcomes, an additional item indicated whether the respondent was not partnered; partnered and their partner was returning to the respondent's origin municipality; or partnered and the partner was returning to his/ her origin municipality (with the respondent). Given the restrictions on the sample (i.e., those who were employed prior to and after moving as well as those who were unemployed after moving), the measure for employment was not included in the model for labor market outcomes.

\section{Analytic Strategy}

To test for the importance of family and friends in return migration (Hypotheses 1-4), we used logistic regression to examine the probability of making a return migration versus moving onward. For Hypotheses 2 and 3, we added interaction terms between (i) the importance of being close to relatives and age group and (ii) the importance of being close to friends and age group (in Table 3, the "Life Course" model). For Hypothesis 4, we included interaction terms between (i) the importance family and urbanicity and (ii) the importance of friends and urbanicity (in Table 3, the "Urbanicity" model). Subsequent analyses on labor market outcomes (Hypotheses 5 and 6) are based on multinomial logistic regression assessing whether return migration is associated with improvement or deterioration in labor market outcomes. No change in labor market outcomes was the reference category. For analyses that include interaction terms, average marginal effects are presented in an Online Supplemental Table.

\section{Results}

\section{Return Migration}

Summary statistics for variables in the models examining the role of family and friends for onward and return migration are shown in Table 1. Column percentages are presented under "Full Sample" and row percentages presented across categories of the dependent variable.

Just over one quarter $(25.9 \%)$ of individuals reported returning to their origin municipality compared with onward migration $(74.1 \%)$. When compared with onward migrants, those who returned to their origin reported a higher importance 
Table 1 Sample characteristics for return vs. onward migration: mean (SD) or percentage $(N=2172)$

\begin{tabular}{|c|c|c|c|c|}
\hline Variables & Full sample & Returned & Moved onward & Difference \\
\hline Repeat migration type & & 25.9 & 74.1 & \\
\hline \multicolumn{5}{|l|}{ Individual/household-level } \\
\hline Age & $44.5(17.2)$ & $41.9(17.7)$ & $45.4(16.9)$ & $* * *$ \\
\hline $18-25$ & 17.2 & 36.1 & 63.9 & \multirow[t]{4}{*}{$* * *$} \\
\hline $26-37$ & 26.0 & 28.1 & 71.9 & \\
\hline $38-59$ & 25.9 & 19.4 & 80.6 & \\
\hline $60-74$ & 30.9 & 23.9 & 76.2 & \\
\hline \multicolumn{5}{|l|}{ Gender } \\
\hline Male & 44.7 & 24.5 & 75.5 & \multirow[t]{2}{*}{ NS } \\
\hline Female & 55.3 & 27.1 & 72.9 & \\
\hline Education & $2.7(1.6)$ & $2.5(1.1)$ & $2.7(1.2)$ & $* * *$ \\
\hline \multicolumn{5}{|l|}{ Partnership status } \\
\hline Not partnered & 44.9 & 31.1 & 68.9 & \multirow[t]{3}{*}{$* * *$} \\
\hline Cohabiting & 19.3 & 23.8 & 76.2 & \\
\hline Married & 35.8 & 20.6 & 79.4 & \\
\hline \multicolumn{5}{|l|}{ Parental status } \\
\hline No children & 77.9 & 26.1 & 74.0 & \multirow[t]{2}{*}{ NS } \\
\hline Children & 22.1 & 25.5 & 74.5 & \\
\hline \multicolumn{5}{|l|}{ Employment status } \\
\hline Employed & 55.0 & 25.5 & 74.5 & \multirow[t]{5}{*}{ NS } \\
\hline Unemployed & 6.2 & 27.4 & 72.6 & \\
\hline Student & 9.8 & 29.7 & 70.3 & \\
\hline Retired & 25.3 & 23.9 & 76.1 & \\
\hline Other & 3.8 & 34.2 & 65.9 & \\
\hline \multicolumn{5}{|l|}{ Housing tenure } \\
\hline Rent & 43.4 & 24.3 & 75.7 & \multirow[t]{3}{*}{$* * *$} \\
\hline Own & 48.9 & 24.8 & 75.2 & \\
\hline Other & 7.7 & 41.9 & 58.1 & \\
\hline Household income in SEK (Log) & $12.3(0.8)$ & $12.2(0.7)$ & $12.3(0.8)$ & $* *$ \\
\hline \multicolumn{5}{|l|}{ Municipal-level } \\
\hline \multicolumn{5}{|l|}{ Urbanicity } \\
\hline Small town or rural & 33.7 & 32.2 & 67.9 & \multirow[t]{3}{*}{$* * *$} \\
\hline Medium town & 40.7 & 26.7 & 73.3 & \\
\hline Large city or suburb & 25.7 & 16.5 & 83.5 & \\
\hline Average housing cost (Log) & $7.4(0.6)$ & $7.3(0.6)$ & $7.5(0.6)$ & $* * *$ \\
\hline Unemployment rate & $10.8(2.5)$ & $11.3(2.5)$ & $10.6(2.4)$ & $* * *$ \\
\hline \multicolumn{5}{|l|}{ Higher education in municipality } \\
\hline No universities & 58.1 & 27.4 & 72.6 & \multirow[t]{2}{*}{ NS } \\
\hline Universities & 41.9 & 23.8 & 76.2 & \\
\hline \multicolumn{5}{|l|}{ Migration motives } \\
\hline Importance of relatives & $1.7(1.4)$ & $2.4(1.2)$ & $1.5(1.4)$ & $* * *$ \\
\hline Importance of friends & $1.6(1.3)$ & $2.2(1.2)$ & $1.5(1.3)$ & $* * *$ \\
\hline
\end{tabular}


Table 1 (continued)

Unweighted data. $N S$ not a statistically significant difference

*0.05, ** $0.01, * * * 0.001$

for friends and family $(p<0.001)$. On average, older adults were less likely to return than young adults $(p<0.001)$. Additionally, there is a significant relationship between urbanicity and return migration versus onward migration $(p<0.001)$.

Table 2 presents the results of a logistic regression predicting return migration compared with migration elsewhere among the sample of migrants $(N=2172)$. In support of Hypothesis 1a, there was a positive relationship between moving back to the origin municipality and respondents assigning high importance to being close to nonresident family [Odds Ratio $(\mathrm{OR})=1.8, p<0.001$ ]. However, our analysis does not provide support for the hypothesis regarding the importance of friendship for return migration (H1b). When controlling for the importance of being close to relatives, the importance of being close to friends was not significantly associated with returning compared to moving onward. Age was associated with return migration, with migrants in all age groups being significantly less likely to return than young adults. We did not find evidence of a relationship between urbanicity and return migration.

Among the control variables, partnered and married individuals were less likely to return than those who were neither partnered nor married. When compared with renters, homeowners and those in other living arrangements were more likely to return migrate than move elsewhere. There was also a positive relationship between the unemployment rate in the destination municipality and return migration there.

Table 3 presents the results of interaction terms between age and the importance of relatives and friends (Life Course) as well as the importance of relatives and friends across rural-urban classifications (Urbanicity). Because the results for the other variables in the models are similar to those in Table 2, we only present the interaction effects. In the Life Course model, the interaction term points to a negative relationship between return migration and family importance among the oldest age group (60-74) when compared to the youngest $(18-25$; $\mathrm{OR}=0.53, p<0.001$.). The interaction term for middle-aged respondents (38-59) was also low and marginally significant $(\mathrm{OR}=0.63, p=0.056)$. This implies the findings are not in line with Hypothesis 2a, which was based on the increased role of family in social networks at older ages, and stated that the importance of family for return migration, compared with onward migration, would increase with age. Rather, the results support the competing Hypothesis 3a, which stated that the importance of family for return migration, compared with onward migration, would decrease with age. For the friendship life course hypotheses, the results supported the opposing Hypothesis $3 b$ - that the importance of friends for return migration increases with age. Among the middle-aged and oldest, those who reported a higher importance for being close to friends were more likely to return migrate than the youngest age group.

In the Urbanicity model, we included interactions between the importance of friends/family and urbanicity. We did not find support for the fourth hypotheses. 
Table 2 Logistic regression for return versus onward migration $(N=2172)$

\begin{tabular}{|c|c|c|}
\hline & Odds ratio & $p$ \\
\hline \multicolumn{3}{|l|}{ Migration motives } \\
\hline Importance of relatives & 1.8 & 0.000 \\
\hline Importance of friends & 1.1 & 0.373 \\
\hline \multicolumn{3}{|l|}{ Individual/household-level } \\
\hline \multicolumn{3}{|l|}{ Age } \\
\hline \multicolumn{3}{|l|}{ 18-25 (reference) } \\
\hline $26-37$ & 0.64 & 0.036 \\
\hline $38-59$ & 0.39 & 0.000 \\
\hline $60-74$ & 0.41 & 0.003 \\
\hline Female & 0.91 & 0.512 \\
\hline Education & 0.90 & 0.180 \\
\hline \multicolumn{3}{|l|}{ Partnership status } \\
\hline \multicolumn{3}{|l|}{ Not partnered (reference) } \\
\hline Cohabiting & 0.62 & 0.027 \\
\hline Married & 0.54 & 0.007 \\
\hline Children & 1.20 & 0.397 \\
\hline \multicolumn{3}{|l|}{ Employment status } \\
\hline \multicolumn{3}{|l|}{ Employed (reference) } \\
\hline Unemployed & 0.65 & 0.182 \\
\hline Student & 0.67 & 0.122 \\
\hline Retired & 0.87 & 0.627 \\
\hline Other & 1.70 & 0.164 \\
\hline \multicolumn{3}{|l|}{ Housing tenure } \\
\hline \multicolumn{3}{|l|}{ Rent (reference) } \\
\hline Own & 1.37 & 0.049 \\
\hline Other & 2.24 & 0.001 \\
\hline Household income in SEK (Log) & 0.97 & 0.770 \\
\hline \multicolumn{3}{|l|}{ Municipal-level } \\
\hline \multicolumn{3}{|l|}{ Urbanicity } \\
\hline \multicolumn{3}{|l|}{ Small town or rural (reference) } \\
\hline Medium town & 0.93 & 0.765 \\
\hline Large city or suburb & 0.77 & 0.426 \\
\hline Average housing cost $(\log )$ & 0.67 & 0.081 \\
\hline Unemployment rate & 1.11 & 0.004 \\
\hline Any universities & 0.74 & 0.146 \\
\hline Pseudo $R^{2}$ & 0.19 & \\
\hline Log pseudolikelihood & $-53,686.23$ & \\
\hline
\end{tabular}

Weighted data. Standard errors corrected for clustered observations at the municipal level 
Table 3 Logistic regression for return versus onward migration: interaction terms $(N=2172)$

\begin{tabular}{|c|c|c|c|c|}
\hline \multirow[t]{2}{*}{ Interaction terms } & \multicolumn{2}{|l|}{ Life course } & \multicolumn{2}{|l|}{ Urbanicity } \\
\hline & Odds ratio & $p$ & Odds ratio & $p$ \\
\hline \multicolumn{5}{|l|}{ Importance of relatives $\times$ age } \\
\hline $26-37 \times$ importance relatives & 0.92 & 0.678 & & \\
\hline $38-59 \times$ importance relatives & 0.68 & 0.056 & & \\
\hline $60-74 \times$ importance relatives & 0.53 & 0.001 & & \\
\hline \multicolumn{5}{|l|}{ Importance of friends $\times$ age } \\
\hline 26-37× importance friends & 1.08 & 0.655 & & \\
\hline $38-59 \times$ importance friends & 1.42 & 0.043 & & \\
\hline 60-74×importance friends & 1.51 & 0.012 & & \\
\hline \multicolumn{5}{|l|}{ Importance of relatives $\times$ urbanicity } \\
\hline Medium town $\times$ importance relatives & & & 0.99 & 0.930 \\
\hline Large city/suburbs $\times$ importance relatives & & & 1.12 & 0.565 \\
\hline \multicolumn{5}{|l|}{ Importance of friends $\times$ urbanicity } \\
\hline Medium town $\times$ importance friends & & & 1.05 & 0.798 \\
\hline Large city/suburbs $\times$ importance friends & & & 1.12 & 0.520 \\
\hline Pseudo $R^{2}$ & 0.20 & & 0.19 & \\
\hline Log pseudolikelihood & $-53,261.43$ & & $-53,663.11$ & \\
\hline
\end{tabular}

Weighted data. Standard errors corrected for clustered observations at the municipal level. Additional controls (see Table 2) are included in the model but not shown within the table

Based on these results, there was no indication that the importance of family for return migration (versus migrating elsewhere) varies by urbanicity.

\section{Labor Market Outcomes}

For analyses examining labor market outcomes as the dependent variable, the sample is smaller because respondents needed to be employed prior to migrating $(N=1056)$. Among migrants who were employed prior to moving, most reported no change in their labor market outcomes (52.7\%). Just over a third reported an improvement and about $13 \%$ reported a labor market deterioration associated with the move. Additional summary statistics for this subsample are presented in Table 4 along with bivariate comparisons across categories of the independent variables.

Table 5 presents the results of the analysis examining the relationship between return migration and labor market outcomes. The findings partially support the fifth hypothesis. Although return migration is indeed associated with a lower likelihood of experiencing a labor market improvement compared to staying the same $(\mathrm{OR}=0.54, p=0.004)$, it is also associated with a lower likelihood of labor market deterioration $(\mathrm{OR}=0.52, p=0.044)$. This suggests that return migration is associated with less individual-level labor market volatility when compared with moving elsewhere. Being close to family as an important consideration for migrating is associated with a higher likelihood of both deterioration and improvement in 
Table 4 Sample characteristics for labor market outcomes: mean (SD) or percentage $(N=1056)$

\begin{tabular}{|c|c|c|c|c|c|}
\hline & Full sample & Deteriorated & Stayed same & Improved & Difference \\
\hline Labor market outcomes & & 13.1 & 52.7 & 34.3 & \\
\hline \multicolumn{6}{|l|}{ Migration type } \\
\hline Returned to municipality & 28.3 & 13.0 & 57.5 & 29.4 & \multirow[t]{2}{*}{ NS } \\
\hline Moved elsewhere & 71.7 & 13.1 & 50.7 & 36.2 & \\
\hline \multicolumn{6}{|l|}{ Individual/household-level } \\
\hline Age & $42.1(13.1)$ & $44.8(13.4)$ & $44.7(13.1)$ & $37.0(11.4)$ & $* * *$ \\
\hline $18-25$ & 8.3 & 11.6 & 33.4 & 54.9 & \multirow[t]{4}{*}{$* * *$} \\
\hline $26-37$ & 34.9 & 11.3 & 46.0 & 42.7 & \\
\hline $38-59$ & 42.1 & 13.5 & 58.9 & 27.6 & \\
\hline $60-74$ & 14.7 & 18.0 & 70.9 & 11.1 & \\
\hline \multicolumn{6}{|l|}{ Gender } \\
\hline Male & 50.0 & 11.2 & 54.2 & 34.7 & \multirow[t]{2}{*}{ NS } \\
\hline Female & 50.0 & 15.0 & 51.1 & 33.9 & \\
\hline Education & $2.9(1.1)$ & $2.8(1.1)$ & $2.8(1.1)$ & $3.1(1.1)$ & $* * *$ \\
\hline \multicolumn{6}{|l|}{ Partnership status } \\
\hline Not partnered & 39.0 & 12.6 & 50.5 & 36.9 & \multirow[t]{3}{*}{ NS } \\
\hline Cohabiting & 21.5 & 10.6 & 50.7 & 38.8 & \\
\hline Married & 39.5 & 14.9 & 55.9 & 29.3 & \\
\hline \multicolumn{6}{|l|}{ Partner return status } \\
\hline Not partnered & 38.6 & 12.5 & 50.5 & 37.0 & \multirow[t]{3}{*}{ NS } \\
\hline No partner return & 50.5 & 13.9 & 53.9 & 32.3 & \\
\hline Partner returned & 10.9 & 11.3 & 54.8 & 33.9 & \\
\hline \multicolumn{6}{|l|}{ Parental status } \\
\hline No children & 67.7 & 12.5 & 52.5 & 35.1 & \multirow[t]{2}{*}{ NS } \\
\hline Children & 32.3 & 14.4 & 53.1 & 32.6 & \\
\hline \multicolumn{6}{|l|}{ Employment status (post-move) } \\
\hline Employed & 94.9 & 8.4 & 55.5 & 36.1 & \multirow[t]{2}{*}{-} \\
\hline Unemployed & 5.1 & 100.0 & - & - & \\
\hline \multicolumn{6}{|l|}{ Housing tenure } \\
\hline Rent & 37.3 & 13.7 & 43.9 & 42.4 & \multirow[t]{3}{*}{$* * *$} \\
\hline Own & 58.1 & 12.5 & 59.9 & 27.5 & \\
\hline Other & 4.6 & 14.6 & 31.3 & 54.2 & \\
\hline Household income in SEK (Log) & $12.5(0.7)$ & $12.5(0.7)$ & $12.6(0.7)$ & $12.4(0.7)$ & $* * *$ \\
\hline Importance of relatives & $1.6(1.4)$ & $1.9(1.4)$ & $1.4(1.4)$ & $1.7(1.4)$ & $* * *$ \\
\hline \multicolumn{6}{|l|}{ Municipal-level } \\
\hline \multicolumn{6}{|l|}{ Urbanicity } \\
\hline Small town or rural & 31.8 & 14.6 & 55.4 & 30.1 & \multirow[t]{3}{*}{$* *$} \\
\hline Medium town & 42.3 & 15.7 & 51.2 & 33.1 & \\
\hline Large city or suburb & 25.9 & 7.0 & 51.7 & 41.4 & \\
\hline Average housing cost (Log) & $7.5(0.6)$ & $7.3(0.6)$ & $7.4(0.6)$ & $7.5(0.6)$ & $* * *$ \\
\hline Unemployment rate & $10.8(2.6)$ & $11.4(2.7)$ & $10.6(2.7)$ & $10.8(2.4)$ & $* *$ \\
\hline \multicolumn{6}{|l|}{ Higher education in municipality } \\
\hline No universities & 56.7 & 13.4 & 58.4 & 28.2 & \multirow[t]{2}{*}{$* * *$} \\
\hline Universities & 43.3 & 12.7 & 45.1 & 42.2 & \\
\hline
\end{tabular}


Table 4 (continued)

Unweighted data. $N S$ not a statistically significant difference

$* 0.05, * * 0.01, * * * 0.001$

labor market conditions. That is, those who reported that family were important for their migration were more likely to experience a change in labor market outcomes, either positive or negative. Thus, the results for Hypothesis 6 suggest that the importance of family for return migration is associated with higher labor market volatility (i.e., a higher likelihood of change in either direction) when compared with onward migration.

Lastly, the importance of being close to relatives does not moderate the relationship between return migration and labor market deterioration. However, there is a marginal relationship for labor market improvement (additional results not shown in tables), suggesting that return migrations where family is of higher importance are associated with improved labor market outcomes $(\mathrm{OR}=1.37, p=0.053)$.

For control variables, compared to the youngest age group in the sample (18-25), those aged 38-59 were less likely to experience a labor market improvement versus staying the same. The oldest respondents in the sample were significantly less likely to experience an improvement rather than stay the same. Those who owned their home were less likely to experience an improvement in their labor market outcomes. Migrants who moved to a municipality with higher rates of unemployment were more likely to experience worse outcomes rather than remain the same. The results did not indicate that men and women experienced changes in labor market outcomes differently.

\section{Sensitivity and Supplemental Analyses}

In addition to the closed-ended items for the importance of being close to family and friends, we ran sensitivity analyses using (binary) measures for whether friends and/or family were identified as actual motives for migration in the open-ended survey items. We also ran additional models without individuals who transitioned to unemployment marked as having experienced a labor market deterioration. In both of these sets of analyses, the results did not differ substantially from the ones we present.

As supplemental analyses, we ran our models separately by gender-the results did not differ substantially between men and women. This similarity between the genders might be connected with Sweden's gender egalitarianism. We also conducted separate analyses for those migrating to urban versus nonurban and rural versus nonrural regions. The results were the same for the models predicting return versus onward migration. For the labor market outcomes models, sample size issues precluded the convergence of the model for urban migrants. However, as in the model for the full sample, among those who moved to rural areas, return migrants had a lower likelihood of labor market improvement. Rural migrants who 
Table 5 Multinomial logistic regression for labor market outcomes $(N=1056)$

\begin{tabular}{|c|c|c|c|c|}
\hline \multirow[t]{2}{*}{ Reference: stayed the same } & \multicolumn{2}{|l|}{ Deteriorated } & \multicolumn{2}{|l|}{ Improved } \\
\hline & Odds ratio & $p$ & Odds ratio & $p$ \\
\hline \multicolumn{5}{|l|}{ Migration type } \\
\hline \multicolumn{5}{|l|}{ Onward migration (reference) } \\
\hline Return migration & 0.52 & 0.044 & 0.54 & 0.004 \\
\hline \multicolumn{5}{|l|}{ Individual/household-level } \\
\hline Importance of relatives & 1.52 & 0.000 & 1.27 & 0.001 \\
\hline \multicolumn{5}{|l|}{ Age } \\
\hline \multicolumn{5}{|l|}{ 18-25 (reference) } \\
\hline $26-37$ & 1.16 & 0.784 & 0.63 & 0.222 \\
\hline $38-59$ & 0.90 & 0.850 & 0.35 & 0.004 \\
\hline $60-74$ & 1.06 & 0.927 & 0.12 & 0.000 \\
\hline Female & 0.79 & 0.308 & 0.80 & 0.163 \\
\hline Education & 1.02 & 0.894 & 1.18 & 0.092 \\
\hline \multicolumn{5}{|l|}{ Partnership status } \\
\hline \multicolumn{5}{|l|}{ Not partnered (reference) } \\
\hline Cohabiting & 0.75 & 0.815 & 1.39 & 0.749 \\
\hline Married & 1.11 & 0.941 & 1.54 & 0.682 \\
\hline \multicolumn{5}{|l|}{ Partner return status } \\
\hline \multicolumn{5}{|l|}{ Partner returned (reference) } \\
\hline Not partnered & 1.08 & 0.954 & 1.39 & 0.752 \\
\hline No partner return & 1.03 & 0.955 & 1.30 & 0.419 \\
\hline Children & 1.09 & 0.749 & 0.98 & 0.920 \\
\hline \multicolumn{5}{|l|}{ Housing tenure } \\
\hline \multicolumn{5}{|l|}{ Rent (reference) } \\
\hline Own & 0.68 & 0.178 & 0.62 & 0.036 \\
\hline Other & 0.82 & 0.766 & 1.55 & 0.265 \\
\hline Household income (Log) & 0.81 & 0.438 & 0.82 & 0.235 \\
\hline \multicolumn{5}{|l|}{ Municipal-level } \\
\hline \multicolumn{5}{|l|}{ Urbanicity } \\
\hline \multicolumn{5}{|c|}{ Small town or rural (reference) } \\
\hline Medium town & 0.69 & 0.217 & 0.72 & 0.225 \\
\hline Large city or suburb & 0.62 & 0.293 & 0.90 & 0.756 \\
\hline Average housing cost (Log) & 1.06 & 0.877 & 1.38 & 0.217 \\
\hline Unemployment rate & 1.20 & 0.006 & 1.08 & 0.093 \\
\hline Any universities & 1.26 & 0.524 & 1.49 & 0.113 \\
\hline Pseudo $R^{2}$ & 0.09 & & & \\
\hline Log pseudolikelihood & $-49,992.46$ & & & \\
\hline
\end{tabular}

Weighted data. Standard errors corrected for clustered observations at the municipal level 
rated family as higher in importance also had a higher likelihood of labor market deterioration.

\section{Discussion and Conclusion}

Drawing on unique data that allowed us to couple register data information with individuals' self-reported importance of social factors for returning, we examined the importance of family and friends in individuals' decisions to return migrate compared with moving elsewhere. We also focused on how this importance differed by age and urbanicity. Given the importance of nonresident family-motivated migration for labor market outcomes (Gillespie et al., 2020), we further examined how return migration (as well as return migration coupled with the importance of family for doing so) impacts labor market outcomes.

Our results lend partial support to Hypothesis 1 . The results show that the importance of being close to nonresident family is indeed associated with a higher likelihood of return migration compared with onward migration. However, the findings do not provide support for our expectation that friends would be an important factor in individuals' decision to return migrate compared with moving onward. While our findings reiterate the important role of family in return migration (Gillespie \& Mulder, 2020), they moreover indicate that family is not a mere by-product of returns for other reasons (e.g., moving to familiar surroundings or being closer to friends), although its importance differs by age.

We proposed competing hypotheses about the importance of family and friends for return migration over the life course. We did not find support for Hypotheses $2 \mathrm{a}$ and $2 \mathrm{~b}$. Based on arguments about the changing roles of family and friends in social networks, these hypotheses stated that the importance of family for return migration would increase with age whereas the importance of friends would decrease. Instead, we found support for the opposing hypotheses, which were based on arguments about the extent to which family and friends would be "available" to return to in the region of origin. At early ages, returns to the origin region are common, often for support from parents. Older migrants are less likely to have parents or adult children at the origin. Therefore, older individuals who move toward their adult children (e.g., for later life care or to be closer to their grandchildren) would be more likely to move onward rather than to return. Likewise, the finding that, for return migration (compared with onward moves), friends increased in importance with age also makes sense. Friends are often of the same generation and, if close family are less likely to be at the origin (i.e., at older ages), friends could become an important feature for return migration. Even though individuals' number of close friends tends to decrease over the life course, satisfaction with friends tends to increase with age (Gillespie et al., 2015a), which might translate into their importance for decisions about where to move.

We did not find support for our fourth hypothesis. The results did not suggest that the importance of family for return migration varied by urbanicity. This null finding might reflect the overall importance of the family, regardless of the type of origin region. As others have shown (Rossi \& Rossi, 1990), family is a source of support 
in times of need, and our findings suggest that the need for support likely transcends geographic characteristics.

Previous work has noted how individuals sacrifice economic returns in order to improve other returns (von Reichert et al., 2011). Contrary to Hypothesis 5-that return migration would be associated with worse labor market outcomes-in our analyses, we found that return migration, compared with onward migration, was associated with a lower likelihood of both labor market deterioration and improvement, suggesting lower labor market volatility. The lower likelihood of improvement is in line with the idea that return migration is frequently motivated by noneconomic benefits and thus less likely leads to such benefits. But the lower likelihood of deterioration does not suggest that return migrants tend to make sacrifices in their career more so than onward migrants. The higher likelihood of labor market outcomes staying the same might be related to the geographic context of our study-labor policies in Sweden could be buffers against labor market precarity, even in the context of migration. Swedish policies toward family support may also decrease the necessity of returning to family for receiving or providing support even if it entails career sacrifices.

At the same time, contrary to Hypothesis 6-that a higher importance placed on being close to family would be associated with worse labor market outcomesthe importance of family was associated with a higher likelihood of improvement as well as deterioration, when compared with staying the same. For deterioration, it might be that family in the origin can help mitigate income loss or that people feel compensated for poorer labor market outcomes with proximity to family. For improvements, family and their networks might assist in reducing barriers to employment, acting as a social resource (Mulder, 2018).

Traditional human capital models of migration focus on how decisions to move are contingent upon economic cost/benefit analyses of moving versus staying (Sjaastad, 1962). This suggests that changes in labor market circumstances are the primary reason why working-age individuals migrate. It also suggests that the natural outcome of such a migration is better labor market outcomes. However, given the importance of family for return migration, we further examined whether and how returning for family-related reasons was linked to labor market outcomes that differ from onward migration. Our findings indicate that return migration where family is ranked high in importance is at least marginally associated with labor market improvements. This lends some support to our speculation above-for those returning to family, the disadvantages of return migration might be offset because the family helps mitigate joblessness, for example.

There are important limitations to our data and approach. First, our results should be interpreted in the context of the Swedish housing and labor market, which surely differ from those in other countries. Moreover, it is likely that labor and housing markets in Sweden have changed since the data were collected more than 10 years ago. Second, although it is not common in Sweden, there could be some cases where the boundaries of the respondent's county of birth changed over time and the county was no longer the same area by the time the adult respondent moved. Third, we assume county of birth to be the same place as where the respondent "grew up" but this may not necessarily be the case. Additionally, in our cross-sectional data, we 
could not capture long-term labor market effects. Indeed, Glaeser and Mare (2001) found that income gains due to migration were not always immediate, but could take several years to accrue. If this was the case, our findings about labor market stability might not hold. Ideally, we would also be able to compare return migrants with nonmigrants (in addition to onward migrants), as well; however, our migrant-only sample does not allow for such comparisons.

From a policy perspective, these results suggest that families and social networks could be viewed as important factors for attracting people to return to their origins. For instance, declining areas considering returning migrants as a target group for repopulation benefit from recognizing the role that family and friends might play in re-attracting people (Cromartie \& Stack, 1989; von Reichert et al., 2014b). A separate research literature examines the impact of migration on families and children, even calling for examinations of how different types of geographic mobilityincluding return migration-impact children and families differently (e.g., Gillespie, 2017). Indeed, some of these individual and family-level outcomes might be instigated by changes in labor market outcomes associated with return migration or the volatility associated with onward migration. This would be an interesting avenue for future research.

Supplementary Information The online version contains supplementary material available at https://doi. org/10.1007/s11113-021-09650-x.

Acknowledgements The authors would like to thank Thomas Niedomysl and Ingela Turner.

Funding This article is based on research funded by the European Research Council under the European Union's Horizon 2020 research and innovation program (Grant 740113).

Open Access This article is licensed under a Creative Commons Attribution 4.0 International License, which permits use, sharing, adaptation, distribution and reproduction in any medium or format, as long as you give appropriate credit to the original author(s) and the source, provide a link to the Creative Commons licence, and indicate if changes were made. The images or other third party material in this article are included in the article's Creative Commons licence, unless indicated otherwise in a credit line to the material. If material is not included in the article's Creative Commons licence and your intended use is not permitted by statutory regulation or exceeds the permitted use, you will need to obtain permission directly from the copyright holder. To view a copy of this licence, visit http://creativecommons.org/licen ses/by/4.0/.

\section{References}

Artamonova, A., Gillespie, B. J., \& Brandén, M. (2020). Geographic mobility among older people and their adult children: The role of parents' health issues and family ties. Population, Space and Place. https://doi.org/10.1002/psp.2371.

Belot, M., \& Ermisch, J. (2009). Friendship ties and geographical mobility: Evidence from Great Britain. Journal of the Royal Statistical Society A, 172(2), 427-442.

Bell, M., Charles-Edwards, E., Bernard, A., \& Ueffing, P. (2018). Global trends in internal migration. In T. Champion, T. J. Cooke, \& I. Shuttleworth (Eds.), Internal migration in the developed world: Are we becoming less mobile? (pp. 76-97). Routledge, Taylor \& Francis Group. 
Bernard, A., Bell, M., \& Charles-Edwards, E. (2016). Internal migration age patterns and the transition to adulthood: Australia and Great Britain compared. Journal of Population Research, 33(2), 123-146. https://doi.org/10.1007/s12546-016-9157-0.

Champion, T. (2012). Testing the return migration element of the 'escalator region' model: An analysis of migration into and out of South East England, 1966-2001. Cambridge Journal of Regions, Economy and Society, 5(2), 255-270. https://doi.org/10.1093/cjres/rsr045.

Cromartie, J. B., \& Stack, C. B. (1989). Reinterpretation of Black return and nonreturn migration to the South 1975-1980. Geographical Review, 79(3), 297-310.

DaVanzo, J. (1981). Repeat migration, information costs, and location-specific capital. Population and Environment, 4(1), 45-73.

DaVanzo, J., \& Morrison, P. A. (1981). Return and other sequences of migration in the United States. Demography, 18, 85-101.

Fielding, A. J. (1992). Migration and social mobility: South East England as an Escalator Region. Regional Studies, 26(1), 1-15.

Gillespie, B. J. (2017). Mobility effects and cumulative mobility Contexts. Ch. 6 in Household mobility in America: Patterns, processes, and outcomes. Palgrave Macmillan.

Gillespie, B. J. (2020). Adolescent intergenerational relationship dynamics and leaving and returning to the parental home. Journal of Marriage and Family, 82(3), 997-1014. https://doi.org/10.1111/jomf. 12630.

Gillespie, B. J., Frederick, D., Harari, L., \& Grov, C. (2015a). Homophily, close friendship, and life satisfaction among gay, lesbian, heterosexual, and bisexual men and women. PLoS ONE, 10(6), e0128900. https://doi.org/10.1371/journal.pone.0128900.

Gillespie, B. J., \& Lei, L. (2020). Intergenerational solidarity, proximity to parents when moving to independence, and returns to the parental home. Population, Space and Place. https://doi.org/10.1002/ psp. 2395 .

Gillespie, B. J., Lever, J., Frederick, D., \& Royce, T. (2015b). Close adult friendships, gender, and the life cycle. Journal of Social and Personal Relationships, 32(6), 709-736. https://doi.org/10.1177/02654 07514546977.

Gillespie, B. J., \& Mulder, C. H. (2020). Nonresident family as a motive for migration. Demographic Research, 42, 399-410. https://doi.org/10.4054/DemRes.2020.42.13.

Gillespie, B. J., Mulder, C. H., \& Eggleston, C. M. (2021). Measuring migration motives with openended survey data: Methodological and conceptual issues. Population, Space and Place. https://doi. org/10.1002/psp.2448.

Gillespie, B. J., Mulder, C. H., \& Thomas, M. J. (2020). Migration for family and labour market outcomes in Sweden. Population Studies. https://doi.org/10.1080/00324728.2020.1800068.

Glaeser, E. L., \& Mare, D. C. (2001). Cities and skills. Journal of Labor Economics, 19(2), 316-342.

Grunfelder, J., Norlen, G., Randall, L., \& Sanchez Gassen, N. (Eds.). (2020). State of the Nordic Region 2020. Nordic Council of Ministers.

Haartsen, T., \& Thissen, F. (2013). The success-failure dichotomy revisited: Young adults' motives to return to their rural home region. Children's Geographies, 12(1), 87-101. https://doi.org/10.1080/ 14733285.2013.850848.

Hank, K., \& Buber, I. (2009). Grandparents caring for their grandchildren: Findings from the 2004 Survey of Health, Ageing and Retirement in Europe. Journal of Family Issues, 30(1), 53-73. https://doi. org/10.1177/0192513X08322627.

Hofferth, S., \& Iceland, J. (1998). Social capital in rural and urban communities. Rural Sociology, 63(4), 574-598.

Kolk, M. (2017). A life-course analysis of geographical distance to siblings, parents, and grandparents in Sweden. Population, Space and Place, 23(3), e2020. https://doi.org/10.1002/psp.2020.

Korpi, M., \& Clark, W. A. V. (2017). Human capital theory and internal migration: Do average outcomes distort our view of migrant motives? Migration Letters, 14(2), 237-250.

Lundholm, E. (2012). Returning home? Migration to birthplace among migrants after age 55. Population, Space and Place, 18(1), 74-84. https://doi.org/10.1002/psp.645.

Michielin, F., Mulder, C. H., \& Zorlu, A. (2008). Distance to parents and geographical mobility. Population, Space and Place, 14(4), 327-345. https://doi.org/10.1002/psp.509.

Mulder, C. H. (2018). Putting family centre stage: Ties to nonresident family, internal migration, and immobility. Demographic Research, 39, 1151-1180. https://doi.org/10.4054/DemRes.2018.39.43.

Mulder, C. H., \& Clark, W. A. V. (2000). Leaving home and leaving the state: Evidence from the United States. International Journal of Population Geography, 6(6), 423-437. 
Mulder, C. H., \& Kalmijn, M. (2006). Geographical distances between family members. In P. A. Dykstra, M. Kalmijn, T. C. M. Knijn, A. E. Komter, A. C. Liefbroer, \& C. H. Mulder (Eds.), Family solidarity in the Netherlands. Dutch University Press.

Mulder, C. H., Lundholm, E., \& Malmberg, G. (2020). Young adults' return migration from large cities in Sweden: The role of siblings and parents.". Population, Space and Place. https://doi.org/10.1002/ psp. 2354 .

Mulder, C. H., Lundholm, E., \& Malmberg, G. (2020). Young adults' migration to cities in Sweden: Do siblings pave the way? Demography, 57, 2221-2224. https://doi.org/10.1007/s13524-020-00934-z

Newbold, B. K., \& Liaw, K. (1990). Characterization of primary, return, and onward interprovincial migration in Canada: Overall and age-specific Patterns. The Canadian Journal of Regional Science, $13,17-34$.

Niedomysl, T. (2011). How migration motives change over migration distance: Evidence on variation across socio-economic and demographic groups. Regional Studies, 45(6), 843-855.

Niedomysl, T., \& Amcoff, J. (2011). Why return migrants return: Survey evidence on motives for internal return migration in Sweden. Population, Space and Place, 17(5), 656-673. https://doi.org/10.1002/ psp.644.

Niedomysl, T., \& Malmberg, G. (2009). Do open-ended survey questions on migration motives create coder variability problems? Population, Space and Place, 15, 79-87. https://doi.org/10.1002/psp. 493.

Olofsson, J., Sandow, E., Findlay, A., \& Malmberg, G. (2020). Boomerang behaviour and emerging adulthood: Moving back to the parental home and the parental neighbourhood in Sweden. European Journal of Population. https://doi.org/10.1007/s10680-020-09557-x.

Pettersson, A., \& Malmberg, G. (2009). Adult children and elderly parents as mobility attractions in Sweden. Population, Space and Place, 15(4), 343-357. https://doi.org/10.1002/psp.558.

Poulin, F., \& Chan, A. (2010). Friendship stability and change in childhood and adolescence. Developmental Review, 30(3), 257-272.

Reher, D. S. (1998). Family ties in Western Europe: Persistent contrasts. Population and Development Review, 24(2), 203-234.

Rossi, A., \& Rossi, P. H. (1990). Of human bonding: Parent child relations across the life course. Aldine.

Shuttleworth, I., Oesth, J., \& Niedomysl, T. (2017). Sweden: Internal migration in a high-migration Nordic country. In T. Champion, T. Cooke, \& I. Shuttleworth (Eds.), Internal migration in the developed world: Are we becoming less mobile? (pp. 203-225). Routledge.

Silverstein, M., Conroy, S. J., Wang, H., Giarrusso, R., \& Bengtson, V. L. (2002). Reciprocity in parentchild relations over the adult life course. Journal of Gerontology, 57B(1), S3-13.

Sironi, M., \& Billari, F. C. (2019). Leaving home, moving to college, and returning home: Economic outcomes in the United States. Population, Space and Place. https://doi.org/10.1002/psp.2302.

Sjaastad, L. A. (1962). The costs and returns of human migration. Journal of Political Economy, 70, 80-93.

Spring, A., Mulder, C. H., Thomas, M. J., \& Cooke, T. J. (2021). Migration after union dissolution in the United States: The role of non-resident family. Social Science Research. https://doi.org/10.1016/j. ssresearch.2021.102539.

Stone, J., Berrington, A., \& Falkingham, J. (2014). Gender, turning points, and boomerangs: Returning home in young adulthood in Great Britain. Demography, 51(1), 257-276. https://doi.org/10.1007/ s13524-013-0247-8.

Thomas, M. J. (2019). Employment, education, and family: Revealing the motives behind internal migration in Great Britain. Population, Space and Place, 25(4), e2233. https://doi.org/10.1002/psp.2233.

Thomas, M. J., \& Dommermuth, L. (2020). Internal migration and the role of intergenerational family ties and life events. Journal of Marriage and Family. https://doi.org/10.1111/jomf.12678.

Thomas, M., Gillespie, B. J., \& Lomax, N. (2019). Variations in migration motives over distance. Demographic Research, 40(38), 1097-1110. https://doi.org/10.4054/DemRes.2019.40.38.

van der Pers, M., \& Mulder, C. H. (2013). The regional dimension of intergenerational proximity in the Netherlands. Population, Space and Place, 19(5), 505-521. https://doi.org/10.1002/psp.1729.

van Diepen, A. M. L., \& Mulder, C. H. (2009). Distance to family members and relocations of older adults. Journal of Housing and the Built Environment, 24, 31-46.

von Reichert, C., Cromartie, J. B., \& Arthun, R. O. (2011). Returning home and making a living: Employment strategies of returning migrants to rural U.S. communities. Journal of Rural and Community Development, 6(2), 35-52. 
von Reichert, C., Cromartie, J. B., \& Arthun, R. O. (2013). Intergenerational relationships and rural return migration. In N. Glasgow \& E. H. Berry (Eds.), Rural aging in 21st century America. (pp. 251-271). Springer.

von Reichert, C., Cromartie, J. B., \& Arthun, R. O. (2014a). Reasons for returning and not returning to rural U.S. communities. The Professional Geographer, 66(1), 58-72. https://doi.org/10.1080/00330 124.2012.725373.

von Reichert, C., Cromartie, J. B., \& Arthun, R. O. (2014b). Impacts of return migration on rural U.S. communities. Rural Sociology, 79(2), 200-226. https://doi.org/10.1111/ruso.12024.

von Reichert, C., \& Rudzitis, G. (1992). Multinomial logistic models explaining income changes of migrants to high-amenity counties. The Review of Regional Studies, 22(1), 25-42.

Voorpostel, M., \& van der Lippe, T. (2007). Support between siblings and between friends: Two world apart? Journal of Marriage and Family, 69(5), 1271-1282. https://doi.org/10.1111/j.1741-3737. 2007.00446.x.

Wall, T., \& von Reichert, C. (2013). Divorce as an influence in return migration to rural areas. Population, Space and Place, 19(3), 350-363. https://doi.org/10.1002/psp.1719.

Wu, C., Fu, Q., Gu, J., \& Shi, Z. (2018). Does migration pay off? Returnees, family background, and selfemployment in rural China. The China Review, 18(1), 59-77.

Zorlu, A., \& Kooiman, N. (2019). Spatial trajectories in early life: Moving on or returning home? Population, Space and Place. https://doi.org/10.1002/psp.2268.

Publisher's Note Springer Nature remains neutral with regard to jurisdictional claims in published maps and institutional affiliations. 